\begin{tabular}{|c|c|c|c|c|c|c|}
\hline \multirow{4}{*}{ Impact Factor: } & ISRA (India) & $=3.117$ & SIS (USA) & $=0.912$ & ICV (Poland) & $=6.630$ \\
\hline & ISI (Dubai, UAE & $=0.829$ & РИНЦ (Russia) & $=0.156$ & PIF (India) & $=1.940$ \\
\hline & GIF (Australia) & $=0.564$ & ESJI $(\mathrm{KZ})$ & $=8.716$ & IBI (India) & $=4.260$ \\
\hline & JIF & $=1.500$ & SJIF (Morocco) & $=5.667$ & OAJI (USA) & $=0.350$ \\
\hline
\end{tabular}

\begin{tabular}{|c|c|}
\hline $\begin{array}{l}\text { SOI: } \frac{1.1 / \mathrm{TA}}{} \\
\text { International Sc } \\
\text { Theoretical } \mathbb{\&} \mathrm{A}\end{array}$ & $\begin{array}{l}\text { IS DOI: } 10.15863 / \mathrm{TAS} \\
\text { cientific Journal } \\
\text { Applied Science }\end{array}$ \\
\hline p-ISSN: 2308-4944 (print) & e-ISSN: 2409-0085 (online) \\
\hline Year: 2019 Issue: 06 & Volume: 74 \\
\hline Published: 13.06 .2019 & http://T-Science.org \\
\hline
\end{tabular}

QR - Issue

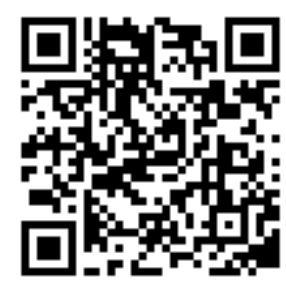

QR - Article

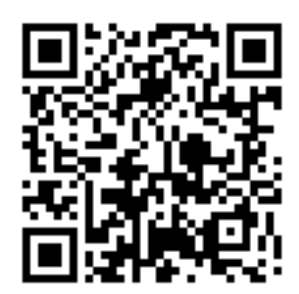

Vadim Andreevich Kozhevnikov

Peter the Great St.Petersburg Polytechnic University

Senior Lecturer

vadim.kozhevnikov@gmail.com

Nikita Mihailovich Slupko

Peter the Great St.Petersburg Polytechnic University

student

nislupko@gmail.com

Anatoliy Vasilievich Sergeev

Peter the Great St.Petersburg Polytechnic University

Assistant Professor

sergeev_av@spbstu.ru

\title{
DESIGN AND DEVELOPMENT OF PERSONAL FINANCE MANAGEMENT SYSTEM
}

\begin{abstract}
This work is dedicated to engineering and implementation of application for personal finance management. It describes existing market solutions and analyses their useful functionality and limitations. Taking this into account we determine functionality of new application and its features that shows product as competitive solution. Then article describes choice of developer tools and analyzing final application.

Key words: personal finance system, web-development.

Language: English

Citation: Kozhevnikov, V. A., Slupko, N. M., \& Sergeev, A. V. (2019). Design and development of personal finance management system. ISJ Theoretical \& Applied Science, 06 (74), 110-115.

Soi: http://s-o-i.org/1.1/TAS-06-74-8 Doi: crossef https://dx.doi.org/10.15863/TAS.2019.06.74.8

\section{Introduction}

Today, more than ever, the issue of rational management and distribution of resources of different kinds is one of the most important. This question arises at different levels - from the management of personal time among schoolchildren to the financial planning of campaigns with billions of authorized capitals. The amount of available information consumed and created goods in the world is constantly growing, but at the same time the complexity of control over them is also growing rapidly.

The idea of competent management of personal finances is not our contemporary at all. It appeared along with the monetary system thousands of years ago and was based on simple basic human needs [1]. Planning your income and expenses allows you not only to get useful predictions, but also to change your own habits: to give up excesses or, on the contrary, to

start investing finances in relevant areas - education, health, family.

For thousands of years people have been counting on paper with pencil. At the turn of the XX and XXI centuries there was an important revolution. Computers have tightly entered our home world and brought new opportunities. Modern systems do not allow us to do anything fundamentally new, but now the construction of graphs and reports has become truly accessible to people. The mobility of the systems allows you to enter the purchase data directly in the store via a mobile application or smartphone browser.

Simplicity, accessibility, elegance, practical benefits, flexibility and mobility have popularized the idea of managing personal finances. Today, hundreds of such applications have millions of downloads in mobile stores and application sites have millions of visits per day.
\end{abstract}




\begin{tabular}{llllll} 
& ISRA (India) $=\mathbf{3 . 1 1 7}$ & SIS (USA) & $=\mathbf{0 . 9 1 2}$ & ICV (Poland) & $=\mathbf{6 . 6 3 0}$ \\
Impact Factor: & ISI (Dubai, UAE) $=\mathbf{0 . 8 2 9}$ & PUHL (Russia) $=\mathbf{0 . 1 5 6}$ & PIF (India) & $=\mathbf{1 . 9 4 0}$ \\
& GIF (Australia) $=\mathbf{0 . 5 6 4}$ & ESJI (KZ) & $=\mathbf{8 . 7 1 6}$ & IBI (India) & $=\mathbf{4 . 2 6 0}$ \\
& JIF & $\mathbf{1 . 5 0 0}$ & SJIF (Morocco) $=\mathbf{5 . 6 6 7}$ & OAJI (USA) & $\mathbf{0 . 3 5 0}$ \\
\hline
\end{tabular}

The application market today is quite large, although inertial - most popular applications have been created for a very long time. This is manifested in the use of outdated technologies, the old inflexible interface and other equally important features. All these reasons create the need for thorough market research, identifying important features and creating a new generation application.

\section{The purpose of the article}

We want to study the existing market offers, to identify their advantages and disadvantages. On this basis, it is necessary to design and implement an application that can become a competitive product in the market. The application should be focused on a wide range of users and solve their financial accounting problems effectively.

\section{Market research}

To determine the current state of the application market in chosen area, we used two review articles with a list of existing solutions [2][3]. Of these, we chose the 4 most popular and large applications with a web version. These services are "Drebedengi" (> 220000 users), Home Money (> 250000 users), EasyFinance (> 350000 users), Cash Organizer (> 100000 users) [4][5][6][7].

As a result of the solutions analysis, the advantages and basic functionality required by the user were identified. These include the ability to add records of spending and income, create various accounts, the ability to view your statistics, create savings targets, create categories of spending. Benefits include multilingual, multi-user mode, intuitive design and the use of modern standards.

The serious shortcomings of existing applications include the partial lack of the above described functionality, the garbage interface, the use of the old technology stack and methods (Flash Player, tabular markup, and others), the inconvenient multiuser mode or the lack of it, the support of a single language, poor user experience.

\section{Platform}

There are three global different platforms for creating an application - a classic application for a personal computer (Windows or Unix-based OS), a web application and a mobile application.

Priority features of the designed application are:

- Accessibility for the user from several devices for convenient instant spending of expenses;

- Availability of service at any point where there is access to the Internet.

Writing a desktop version of an application limits application mobility and, obviously, does not solve our needs.

Mobile applications are a good modern version of the application. Today, most of the traffic is consumed through mobile devices, and mobile applications most conveniently convey the necessary content to the consumer [8]. However, there is a crossplatform problem - to properly reach an audience, it is necessary to write at least two applications for IOS and Android. In addition, the development of a single mobile application makes it impossible for the end user to use the application from a personal computer.

Finally, there is a universal solution in the form of a modern web application. The advantages of this option stem from the disadvantages of the above alternatives:

- cross-platform in nature, it is enough to write the application once and it will be available from any device with a browser;

- undemanding of resources - the application does not require installation;

- mobility, providing access to the service wherever there is a mobile Internet;

- indicators of speed and cost of development are also very good, because we need to write only one application instead of several for each platform.

Thus, the web application is the ideal solution in chosen area.

\section{Architecture}

It is important for us not only to transfer calculations from the client, but also to store a large amount of user data. At the same time, we can optimize the number of requests to the server by adding light scripts that serve the user and access the server only at the moment of real need. Using asynchronous interaction mechanisms, we will achieve optimal performance and a better experience for the user.

Thus, classical n-tier architecture is suitable for us. It consists of three components:

- a client that serves as an entry point for a user, displays data and generates queries;

- a server that receives requests, processes data, stores and withdraws them from the database, and generates and sends a response to the client;

- a database storing all user data and metadata.

\section{Server}

We will be defined with requirements to our server. Our application does not imply any complex calculations. The main priority is the fast processing of requests from the client. The initial application project should be designed to handle a large number of simultaneous requests - the vast majority of them will come to add and retrieve records from the database.

The server could be implemented with C-like language - C\# or Java, but developing with them takes multiple times more than in other languages. It is worthwhile to use these productive, but heavy tools when writing a server of an extremely high-loaded application that performs complex data processing. 


\begin{tabular}{llllll} 
& ISRA (India) $=\mathbf{3 . 1 1 7}$ & SIS (USA) $=\mathbf{0 . 9 1 2}$ & ICV (Poland) & $\mathbf{= 6 . 6 3 0}$ \\
Impact Factor: & ISI (Dubai, UAE) $=\mathbf{0 . 8 2 9}$ & PUHЦ (Russia) $=\mathbf{0 . 1 5 6}$ & PIF (India) & $=\mathbf{1 . 9 4 0}$ \\
& GIF (Australia) $=\mathbf{0 . 5 6 4}$ & ESJI (KZ) & $\mathbf{8 . 7 1 6}$ & IBI (India) & $=\mathbf{4 . 2 6 0}$ \\
& JIF & $\mathbf{1 . 5 0 0}$ & SJIF (Morocco) $=\mathbf{5 . 6 6 7}$ & OAJI (USA) & $\mathbf{0 . 3 5 0}$ \\
\hline
\end{tabular}

The classic server language for a long time was PHP. With the release of new versions, many problems were fixed in it, because of which this language was scolded by the community. However, this language still encourages the use of bad practices and crutches, and innovations are created more to facilitate the lives of programmers who support PHP projects than to attract the attention of new projects. Today, the share of new projects that use PHP is inexorably decreasing. Choosing a tool for a new project, we are forced to focus on its prospects and trends and improvements.

One of the most promising languages today is NodeJS [9]. This is a great tool to handle a large number of asynchronous requests and simple operations on the server. The Node API is written in $\mathrm{C}++$, which provides high performance. Node is simple and transparent to use, its syntax is almost identical to JavaScript, which will be written frontend, which allows the developer to easily move from server development to client development and back. Node has an excellent package manager with a huge number of user libraries to install. Re-use of a quality code, approved and tested by thousands of developers, allows you to abstract from details and focus on important aspects - architecture, useful functionality, application ideology.

Node works fine in conjunction with the Express framework and any settings on it, for example, loopback [10]. The framework provides a flexible and easily customizable API, simplifies writing handlers, and communicates with databases. All this allows you to write high-quality and productive code with minimal time, labor and financial costs. Express is the most popular NodeJS server solution. This niche he occupied not by chance - the framework is easy and fast, while there are no compatibility issues with other packages.

NodeJS and Express are the ideal tool for developing an application based on the criteria specified. What is also important, the Node community is very active, there is good documentation on this technology and a lot of educational and auxiliary literature both on the basic basics of the language, and the design patterns and good practice when developing. By virtue of the above advantages, we will use Node as a back-end development technology.

\section{Client}

We will use HTML5 as our markup language. It is modern standard that has no serious competitors.
For CSS, you can use the SASS or SCSS preprocessors. Reducing the time to write your own styles allows you to focus on the design of the interface, rather than its implementation. We try to use the OOP approach as often as possible to manage abstractions, rather than specific implementations, so using the CSS Modules pattern will be an excellent practice for separating code into structural and stylistic components.

To design an application, it is advisable to use one of the popular MVC frameworks for front-end development. Today on the market we see three such tools: Angular, React and Vue.

We will use React as a flexible and extremely productive library. Moreover, we are working with the advanced technology React Hooks, which will make our code easy, simple and productive.

Let's talk about the popular bundle React + Redux. Redux allows you to store all data in one place and access the store as a single point; data is not stored in components locally. However, Redux has a number of drawbacks, which in our case collectively outweigh the benefits. First of all, this is a significant increase in the amount of code, the complexity of which grows with each new line. In the conditions of a team of one person and tight deadlines, it is necessary to observe and balance the performance and speed of development. Further, Re-dux, being the only monolithic repository, risks storing up-to-date irrelevant data. At the same time, we don't need to store "undo" states, which is another argument against using Redux. As an alternative, we will use several contexts that are connected to the components using the use Conext Hook.

\section{Data Base}

Today, there are two main directions in the way information is presented and stored in databases relational (SQL) and non-relational (NoSQL). Their selection is determined by the requirements provided in the data. In the case of relational databases, this is so-called ACID - Atomicity, Consistency, Isolation, Durability. The choice of non-relational bases is determined by the requirements for flexibility, scalability and speed of access to data. The data can be stored without visible logical connections, as it always happens with the data in the SQL solution, where the base schema is represented by entities and relationships between them. When choosing a solution for your project, you need to understand the absence of a panacea - there is no perfect solution, you always have to sacrifice either stability or speed in one form or another. 


\begin{tabular}{llllll} 
& ISRA (India) $=\mathbf{3 . 1 1 7}$ & SIS (USA) & $=\mathbf{0 . 9 1 2}$ & ICV (Poland) & $=\mathbf{6 . 6 3 0}$ \\
Impact Factor: & ISI (Dubai, UAE) $=\mathbf{0 . 8 2 9}$ & PUHL (Russia) $=\mathbf{0 . 1 5 6}$ & PIF (India) & $=\mathbf{1 . 9 4 0}$ \\
& GIF (Australia) $=\mathbf{0 . 5 6 4}$ & ESJI (KZ) & $=\mathbf{8 . 7 1 6}$ & IBI (India) & $=\mathbf{4 . 2 6 0}$ \\
& JIF & $\mathbf{1 . 5 0 0}$ & SJIF (Morocco) $=\mathbf{5 . 6 6 7}$ & OAJI (USA) & $\mathbf{0 . 3 5 0}$ \\
\hline
\end{tabular}

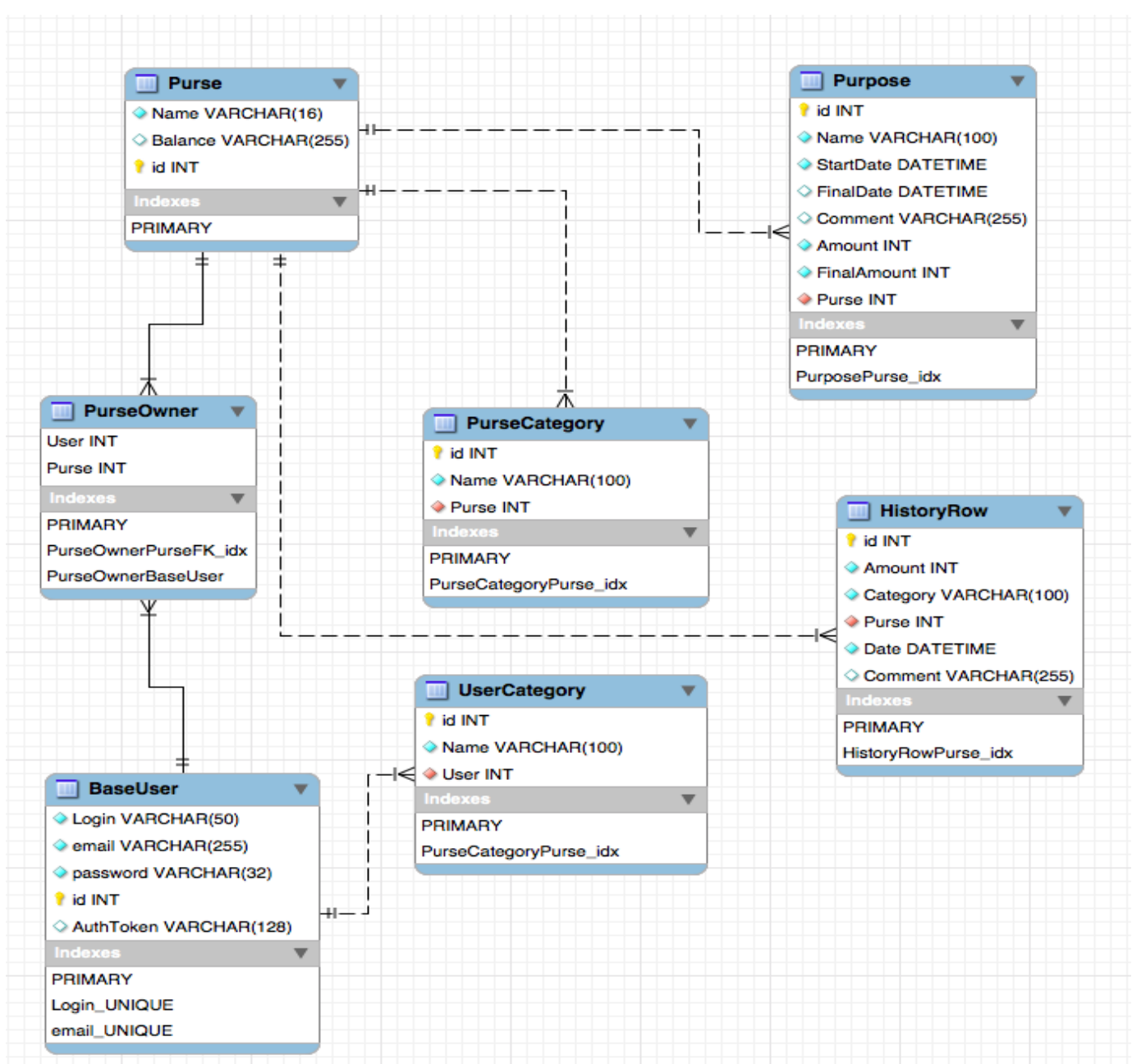

Figure 1 - Physical database scheme

For us, the first priority is the consistency and reliability of the data obtained. Speed, which increases by a fraction of a second, is not so critical for us, as in multimedia applications of high load. Scaling up an application is not so often the case; it will be fairly easy to do with its initial size - in the case of a relational solution, we will need about a dozen entities.

As a relational management system, we will choose MySQL as the most popular solution at the moment.

Based on the functionality of the application, we create a database schema. It consists of 7 tables. This model will be implemented with Loopback technology - Juggler. All data scheme is described is JSON-file and is used on server as global data model.
Every entity will have own API methods. Juggler use this json model to create physical model and exploit it later. You could see this scheme above (Fig. 1).

\section{Application}

After implementation we have to cover our project by functional tests. Main user scenario should test all features of application, such as registration, authorizing, searching history, adding new money account, adding new category, adding people to managing this account in cooperate, adding new financial purpose, analyzing statistics of chosen account. Here are some figures representing these steps (Fig. 2-4). 


\begin{tabular}{llllll} 
& ISRA (India) $=\mathbf{3 . 1 1 7}$ & SIS (USA) $=\mathbf{0 . 9 1 2}$ & ICV (Poland) & $=\mathbf{6 . 6 3 0}$ \\
Impact Factor: & ISI (Dubai, UAE) $=\mathbf{0 . 8 2 9}$ & PUHЦ (Russia) $=\mathbf{0 . 1 5 6}$ & PIF (India) & $=\mathbf{1 . 9 4 0}$ \\
& GIF (Australia) $=\mathbf{0 . 5 6 4}$ & ESJI (KZ) & $=\mathbf{8 . 7 1 6}$ & IBI (India) & $=\mathbf{4 . 2 6 0}$ \\
& JIF & $\mathbf{1 . 5 0 0}$ & SJIF (Morocco) $=\mathbf{5 . 6 6 7}$ & OAJI (USA) & $\mathbf{0 . 3 5 0}$ \\
\hline
\end{tabular}

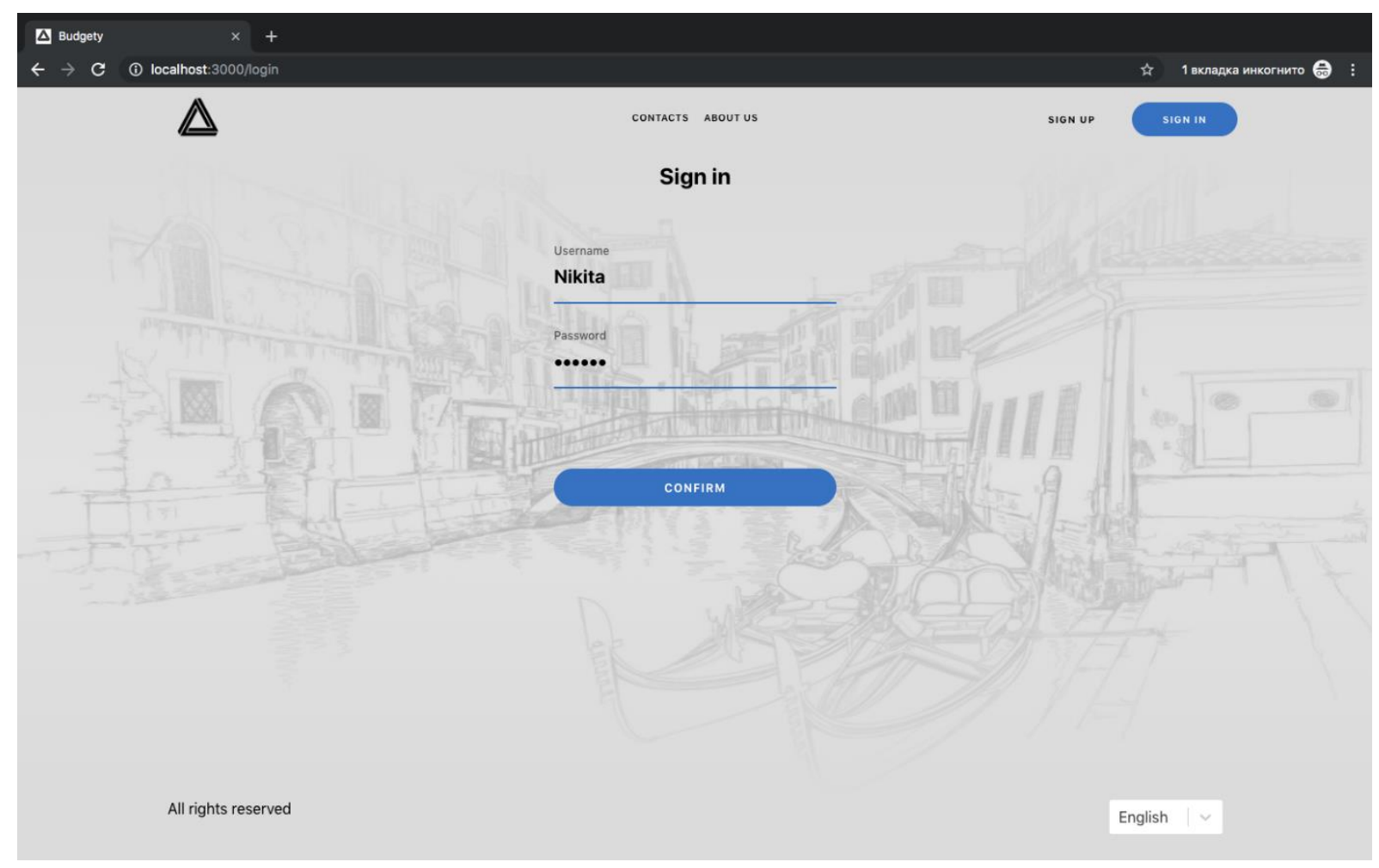

Figure 2 - Authorization Page

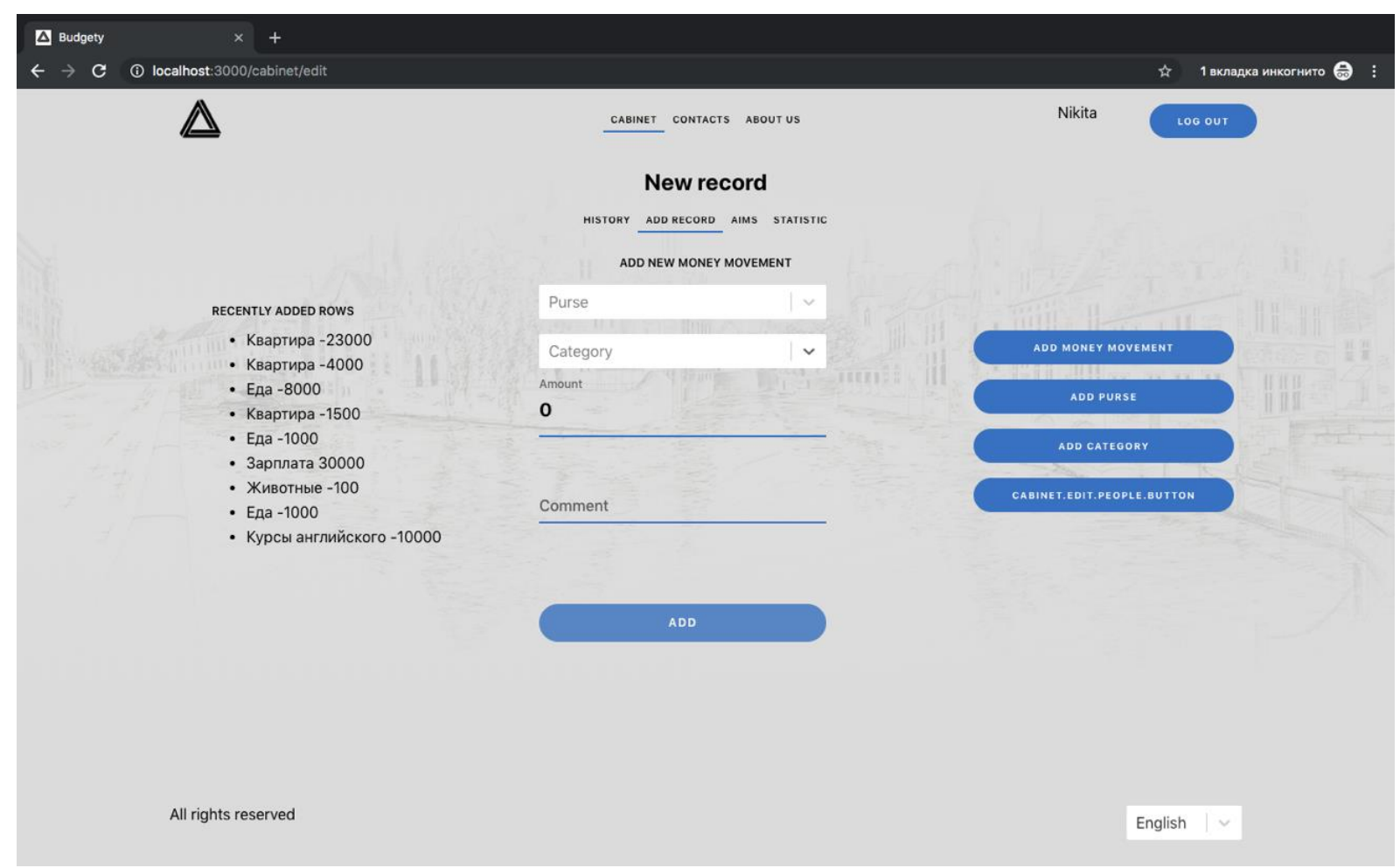

Figure 3 - Adding new record of incoming finance 


\begin{tabular}{llllll} 
& ISRA (India) $=\mathbf{3 . 1 1 7}$ & SIS (USA) & $=\mathbf{0 . 9 1 2}$ & ICV (Poland) & $=\mathbf{6 . 6 3 0}$ \\
Impact Factor: & ISI (Dubai, UAE) $=\mathbf{0 . 8 2 9}$ & PUHL (Russia) $=\mathbf{0 . 1 5 6}$ & PIF (India) & $=\mathbf{1 . 9 4 0}$ \\
& GIF (Australia) $=\mathbf{0 . 5 6 4}$ & ESJI (KZ) & $=\mathbf{8 . 7 1 6}$ & IBI (India) & $=\mathbf{4 . 2 6 0}$ \\
& JIF & $\mathbf{1 . 5 0 0}$ & SJIF (Morocco) $=\mathbf{5 . 6 6 7}$ & OAJI (USA) & $\mathbf{0 . 3 5 0}$ \\
\hline
\end{tabular}

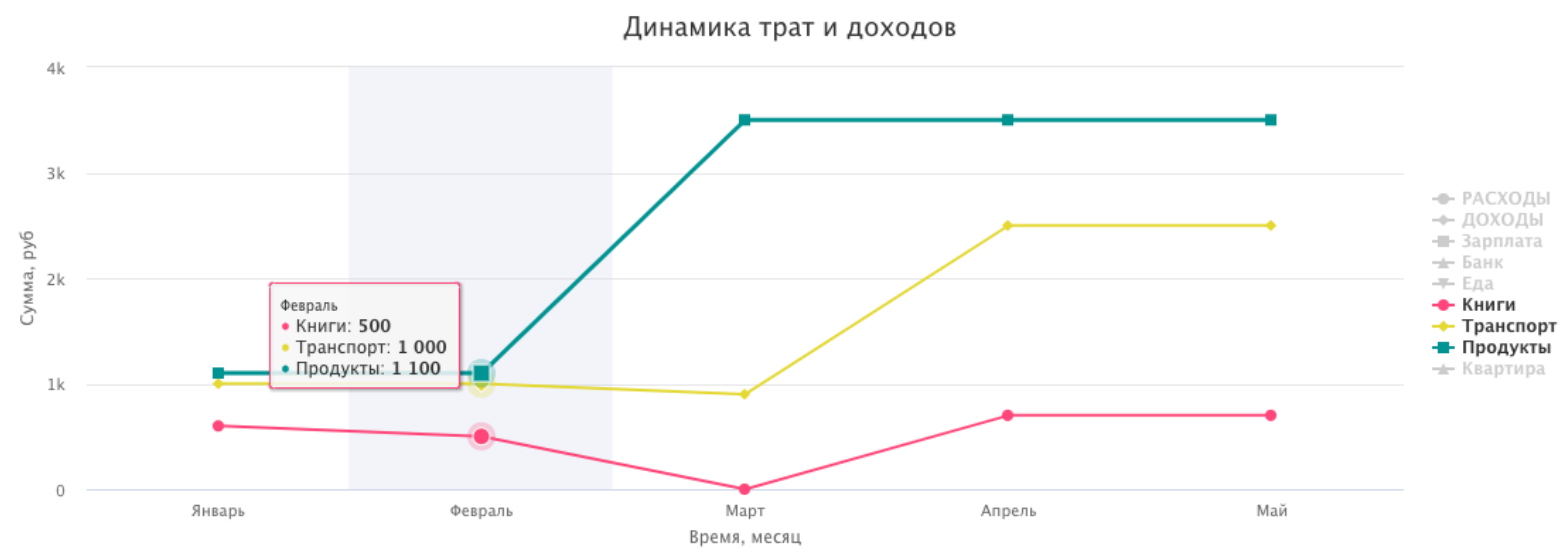

Figure 4 - Fragment of statistic page

\section{Conclusion}

The developed application meets all the requirements [11]. It is ergonomic, easy and satisfies the basic needs of the consumer. Moreover, it is not inferior to competitors in the market and even surpasses some of them in functionality. Conclusions about the choice of tools can be used when designing similar applications.

\section{References:}

1. Frolova, T. A. (2007). Finansy i credit: conspect lekciy. Taganrog: TTI UFU. Retrieved April 12, 2019, from http://www.aup.ru/books/m171

2. (n.d.). Lifehacker. Article «9 samyh udobnyh programm dlya vedeniya semejnogo byudzheta». Retrieved April 14, 2019, from https://lifehacker.ru/family-budget/

3. (n.d.). Startpack. Retrieved April 14, 2019, from https://startpack.ru/category/personal-finance

4. (n.d.). Drebedengi. Retrieved April 15, 2019, from https://www.drebedengi.ru/

5. (n.d.). HomeMoney. Retrieved April 15, 2019, from https://homemoney.ua/app/

6. (n.d.). EasyFinance. Retrieved April 15, 2019, from https://easyfinance.ru/
7. (2019). CashOrganizer. Retrieved April 15, 2019, from https://www.cashorganizer.com/rus/

8. (n.d.). Web-canape. Aritcle «Internet 2017-2018 v mire i v Rossii: statistika i trendy». Retrieved April 16, 2019, from https://www.webcanape.ru/business/internet-2017-2018-v-mirei-v-rossii-statistika-i-trendy/

9. (n.d.). Official NodeJS documentation. Retrieved April 16, 2019, from https://js$\underline{\text { node.ru/ }}$

10. (n.d.). Official Loopback documentation. Retrieved April 17, 2019, from https:/loopback.io

11. (n.d.). GitHub repo of project. Retrieved June 3, 2019, from https://github.com/Nislupko/budgety/ 